\title{
CD44-shRNA recombinant adenovirus inhibits cell proliferation, invasion, and migration, and promotes apoptosis in HCT116 colon cancer cells
}

\author{
SOO YOUNG LEE ${ }^{1}$, KYUNG AE KIM ${ }^{1}$, CHANG HYUN KIM ${ }^{1}$, \\ YOUNG JIN KIM ${ }^{1}$, JAE-HYUK LEE ${ }^{2}$ and HYEONG ROK KIM ${ }^{1}$ \\ ${ }^{1}$ Division of Colorectal Surgery, Department of Surgery and ${ }^{2}$ Department of Pathology, \\ Chonnam National University Medical School and Hwasun Hospital, \\ Hwasun-gun, Jeonnam 58128, Republic of Korea
}

Received August 25, 2016; Accepted October 24, 2016

DOI: $10.3892 /$ ijo.2016.3801

\begin{abstract}
The cell-surface glycoprotein CD44 is closely associated with cell proliferation, tumor invasion, and metastasis. Previous studies have reported that knockdown of CD44 with short hairpin RNA (shRNA) reduced cell proliferation and migration, and induced apoptosis. However, more efficient means of delivering small interference RNA are still necessary. We developed an in vitro model of CD44-shRNA recombinant adenovirus (Ad-CD44-shRNA) and evaluated its ability to alter tumor invasion, migration, and apoptosis in human colon cancer cells. An shRNA against CD44 was used for knockdown of CD44 expression, and recombinant adenovirus was constructed using AD293 cells. The Ad-CD44-shRNA-treated HCT116 colon cancer cells showed a significant decrease in cell proliferation, migration, and invasion, while apoptosis was increased. The Ad-CD44-shRNA also decreased the phosphorylation of Akt and GSK-3 $\beta$. The levels of Bcl-2 and Bcl-xL expression were downregulated, whereas the expression levels of Bax, cleaved caspase-3 and -9, and PARP were increased in Ad-CD44-shRNA-treated colon cancer cells. These results support the feasibility of an adenovirus-mediated RNA interference therapy targeting human colon cancer via the CD44 as a potential future therapeutic intervention.
\end{abstract}

\section{Introduction}

Colorectal cancer is one of the most common malignancies causing mortality in the world (1). However, current knowledge of molecular carcinogenesis in the development of colorectal

Correspondence to: Dr Hyeong Rok Kim, Department of Surgery, Chonnam National University Medical School and Hwasun Hospital, 322 Seoyang-ro, Hwasun-eup, Hwasun-gun, Jeonnam 58128, Republic of Korea

E-mail: drkhr@chonnam.ac.kr

Key words: CD44, recombinant adenovirus, colon cancer cancer is still limited. Although significant advances have been achieved, more effective therapeutic options for advanced colorectal cancer are still needed, and many efforts have been made to develop novel treatments for targeting tumor-specific genes.

Emerging evidence suggests that specific sub-populations of cancer cells with stem cell characteristics within the bulk of tumors are implicated in the pathogenesis of heterogeneous malignant tumors (2-4). To study the behavior of cancer stem cells (CSCs), markers for prospective isolation of CSCs are crucial. CD44 has been proposed as one of the CSC markers of colorectal cancer $(2,4,5)$. CD44 is a transmembrane glycoprotein acting as a cell adhesion molecule through the binding to hyaluronic acid, and plays a key role in remodeling and degradation of hyaluronic acid (4). Furthermore, CD44 is involved in fundamental aspects of cancer cell biology such as tumor stem cell phenotype, cell adhesion, invasion, and metastasis (6). Several studies have shown that CD44 expression was associated with tumor progression, metastasis, and poor prognosis (7-10).

Recent studies have reported that knockdown of CD44 resulted in the inhibition of tumor growth and metastasis (11-13). In our previous studies, we have shown that CD44 enhanced the epithelial-mesenchymal transition, which is associated with colon cancer invasion (14), and that knockdown of CD44 expression using inducible short hairpin RNA (shRNA) significantly reduced cell proliferation, invasion, and migration (13). The therapeutic effect of RNA interference depends on the stability and tissue specificity of small interference RNA (siRNA) and the efficiency of siRNA transduction. We have previously used plasmids to suppress CD44 expression (13); however, the efficiency of plasmid delivery remains poor. Therefore, more efficient means of delivering therapeutic siRNA are necessary. One promising therapeutic modality is the use of oncolytic viruses, which have cancer specificity and also act as a vector for stable introduction of siRNA $(15,16)$.

Here, we developed an in vitro model using CD44-shRNA recombinant adenovirus, and evaluated the impact of CD44 knockdown adenovirus on proliferation, invasion, migration, and apoptosis of colon cancer cells. 


\section{Materials and methods}

Cell culture. The HCT116 human colon cancer cells were obtained from the American Type Culture Collection (ATCC, Manassas, VA, USA). The cells were routinely maintained in complete medium (DMEM; Lonza, Walkersville, MN, USA) supplemented with $10 \%$ fetal bovine serum (FBS; Biowest, Nuaillé, France), $50 \mathrm{U} / \mathrm{ml}$ penicillin, and $50 \mu \mathrm{g} / \mathrm{ml}$ streptomycin (Lonza) at $37^{\circ} \mathrm{C}$ in a humidified incubator with $5 \% \mathrm{CO}_{2}$.

Construction of shRNA-CD44 plasmid. The shRNA with vector was purchased from OriGene (OriGene Technologies, Inc., Rockville, MD, USA). The shRNA-CD44 (sense: GACAG AAAGCCAAGTGGACTCAACGGAGA) and pGFP-V-RS vectors, the latter of which contained an ineffective shRNA cassette against GFP, were used for knockdown of CD44 expression.

Construction of recombinant adenovirus. The human shRNA targeting the CD44 sequence and a negative control scrambled sequence were each amplified by polymerase chain reaction (PCR) from plasmids containing the 29-mer shRNA construct

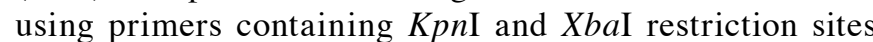
(Enzynomics, Daejeon, Korea). Purified (Qiagen, Valencia, CA, USA) PCR products and adenovirus shuttle plasmids (Agilent Technologies, Palo Alto, CA, USA) were digested with $K p n \mathrm{I}$ and $X b a \mathrm{I}$, ligated with T4 DNA ligase (Promega, Madison, WI, USA), and then transformed into DH5a chemically competent $E$. coli. Miniprepped DNA of the different clones was analyzed on a $0.8 \%$ agarose gel and the correct clones were confirmed by DNA sequencing.

Clones carrying the correct target sequences were selected, linearized with PmeI, subcloned into the pAdEasy-1 backbone, and transformed into BJ5183 bacteria. Recombinant adenoviral plasmids were selected against kanamycin and screened by diagnostic digestions. These plasmids were then digested by $P a c I$, and the larger fragments were transfected using Lipofectamine 2000 (Invitrogen, Carlsbad, CA, USA) into AD293 cells (Stratagene, La Jolla, CA, USA). After 11-13 days, the recombinant adenoviruses were collected after freeze-thaw lysis of the AD293 cells. The primary viral stock was used to infect new AD293 cells for 2-3 days to produce a bulk viral stock. Infected cells exhibiting cytopathic effects were lysed for collection of the virus.

Viral particles were purified and concentrated using the Vivapure AdenoPACK ${ }^{\mathrm{TM}} 20$ RT (Sartorius Stedim Biotech, Göttingen, Germany) kit. The viral particle concentration was determined by measuring absorbance at $260 \mathrm{~nm}$, and a standard $\mathrm{TCID}_{50}(50 \%$ tissue culture infective dose) assay was performed on AD293 cells to determine the infectious virus titer (17). Purified viral particles were stored at $-70^{\circ} \mathrm{C}$ until use.

Adenoviral infection. The HCT116 colon cancer cells were seeded onto a 6 -well plate at a density of $0.1 \times 10^{6}$ cells $/ \mathrm{ml}$, cultured overnight, and infected with serially diluted concentrations of recombinant adenovirus. After a 24-h incubation, the previous growth medium was removed and fresh complete growth medium was added, and treated with adenoviral aliquots with or without shRNA-CD44.
Table I. Primers for RT-PCR.

\begin{tabular}{llc}
\hline Protein & Primers & Sequences \\
\hline CD44 & Forward & 5'-GAA TAT AAC CTG CCG CTT TG-3' \\
& Reverse & 5'-CTG AAG TGC TGC TCC TTT CAC-3' \\
GAPDH & Forward & 5'-ACC ACA GTC CAT GCC ATC AC-3' \\
& Reverse & 5'-TCC ACC ACC CTG TTG CTG TA-3' \\
\hline
\end{tabular}

Reverse transcription PCR (RT-PCR) analysis. Total RNA was isolated from cells with TRIzol reagent (Invitrogen) according to the manufacturer's instructions. The quantity and purity of total RNA were determined by measuring absorbance at 260 and $280 \mathrm{~nm}$ using the Nanodrop ND-1000 spectrophotometer (BCM, Houston, TX, USA). Next, cDNA was synthesized from $3 \mu \mathrm{g}$ total RNA using Oligo(dT) (Promega) and reverse transcriptase (Beams Biotech, Seongnam, Korea). PCR amplification of cDNA was performed using gene-specific primers (Table I) and nTaq DNA polymerase (Enzynomics, Daejeon, Korea). PCR products were separated on a $1 \%$ agarose gel, visualized and photographed under UV light.

Western blotting. Total cell extracts were lysed in cell lysis buffer (Cell Signaling Technology, Inc., Danvers, MA, USA) with a protease inhibitor cocktail (Roche, Basel, Switzerland). Protein concentrations were determined by a BCA protein assay (Thermo Fisher Scientific, Rockford, IL, USA). The protein was separated by $10 \%$ SDS-PAGE and transferred onto a PVDF (polyvinylidene fluoride) membrane (Millipore, Billerica, MA, USA). The membranes were incubated for $1 \mathrm{~h}$ in blocking solution [5\% skim milk in TBS with $0.1 \%$ Tween-20 (TBST)] and sequentially blotted with the following primary antibodies: anti-CD44 (R\&D Systems, Minneapolis, MN, USA), anti-GAPDH (Aviva Systems Biology, San Diego, CA, USA), anti-AKT, anti-phospho-AKT (Ser/Thr), antiphospho-GSK-3 $\beta$, anti- $\beta$-catenin, anti-Bax, anti-Bcl-2, anti-Bcl-xL, anti-caspase-3, anti-phospho-caspase-3, anticleaved-caspase-3, anti-caspase-9, anti-phospho-caspase-9, anti-cleaved-caspase-9, anti-PARP poly(ADP-ribose) polymerase, and anti-cleaved-PARP (Cell Signaling Technology) at $4^{\circ} \mathrm{C}$ overnight. After rinsing in TBST $(0.1 \%)$, membranes were incubated with horseradish peroxidase-labeled antirabbit (Thermo Fisher Scientific) or anti-mouse IgG secondary antibodies (Cell Signaling Technology) at room temperature for $1 \mathrm{~h}$. The blot was detected by ECL (enhanced chemiluminescence) of an HRP substrate (Millipore) on an image reader (Ras4000, Fujifilm, Tokyo, Japan).

Cell viability assay. The viability of treated cells was measured using a Cell Counting Kit-8 (CCK-8; Dojindo, Kumamoto, Japan). Cells were plated into 96-well plate at 5,000 cells/well one day prior to the viral transduction. Then, cells were infected with the recombinant adenoviruses for 1 day, followed by medium replacement. Cell growth and viability were assayed 4-5 days post-infection. For cell viability assay, the cells are incubated with reagents from the CCK- 8 kit for $1 \mathrm{~h}$ and the absorbance was measured at $450 \mathrm{~nm}$ in a microplate reader 
A
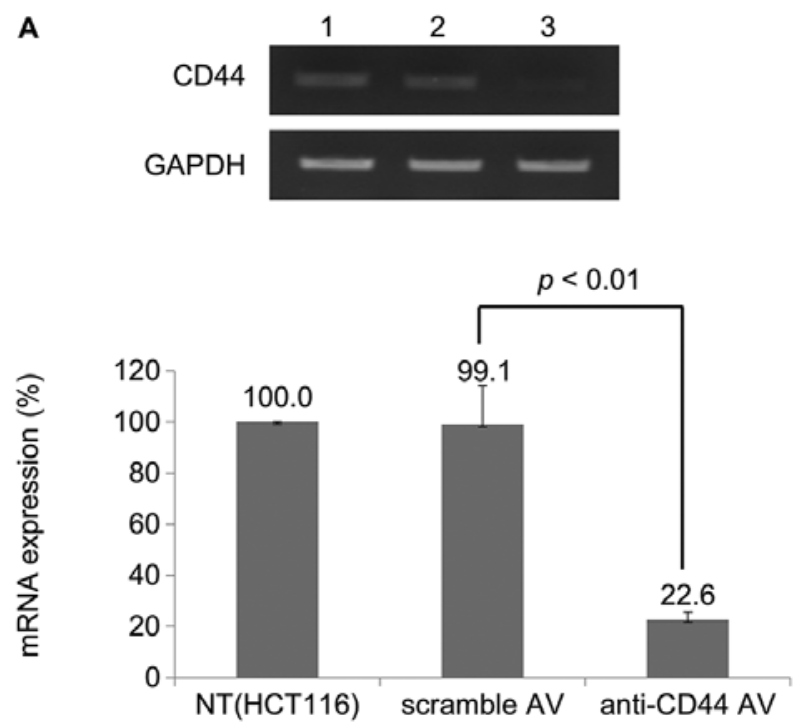

B
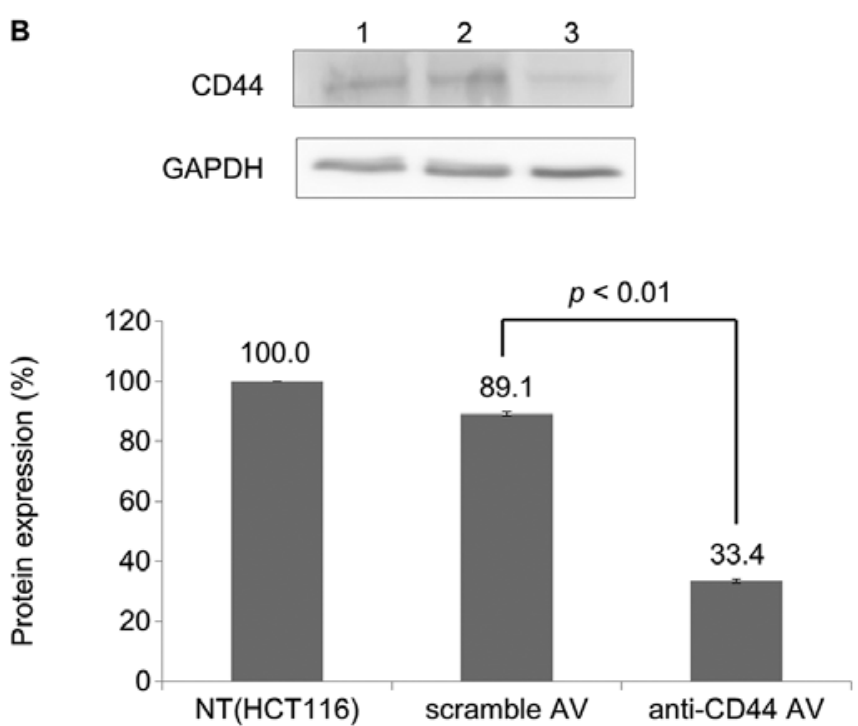

Figure 1.CD44 expression detected by (A) RT-PCR and (B) western blotting, with GAPDH as an internal control. Lane 1, non-treated WT cells (HCT116). Lane 2, cells infected with scramble Ad. Lane 3, cells infected with Ad-CD44-shRNA. Bands were analyzed and quantified by densitometry and the CD44/GAPDH ratio was evaluated.

(BioTek, Winooski, VT, USA). Each sample was assayed in triplicate, and each experiment was repeated at least twice.

Flow cytometry analysis. Apoptosis was quantified using flow cytometry after being stained with APC (allophycocyanin)labeled Annexin V and 7-amino-dactinomycin (BD Biosciences, San Diego, CA, USA). We analyzed for intact cells (Annexin V/7AAD-double-negative), early apoptotic cells (Annexin V-positive), and late apoptotic cells or necrotic cells (Annexin V/7AAD-double-positive). The cells were plated in 6 -well plates at of 200,000 cells/well prior to infected with the recombinant adenoviruses for 4-5 days. Both uninfected and infected HCT116 cells were trypsinized, washed twice with cold PBS, and resuspended in $1 \mathrm{X}$ binding buffer (BD Biosciences). Analysis of $400 \mu \mathrm{l}$ of this cell resuspension was performed on a fluorescence active cell sorting (FACS)Calibur flow cytometer (Becton-Dickinson, San Jose, CA, USA) using the CellQuest version 3.3 software (Becton-Dickinson).

Cell migration assay. Cells were cultured in 6-well plates and infected with the recombinant adenoviruses for 24-48 h. The infected HCT116 cells were then seeded in cultureinserts (2x0.22 $\mathrm{cm}^{2}$; IBIDI GmbH, Martinsried, Germany) at $5 \times 10^{4}$ cells/well. To create a cell-free gap, Culture-Inserts were gently removed using sterile tweezers after a $24-\mathrm{h}$ incubation. The progress of cell migration into the cell-free gap was photographed at 0,20 , and $40 \mathrm{~h}$ using an inverted microscope. The distance between gaps was measured using the Focus Lite Ver 2.90 (Focus, Daejeon, Korea) software after three random sites were photographed.

Cell invasion assay. Cell invasion assays were carried out using 24-well Transwell filters with $8-\mu \mathrm{M}$ pores (Coring Inc., NY, USA). Transwell filters were coated with $500 \mu \mathrm{g}$ Matrigel/ DMEM for 3-4 h and unbound material was aspirated at room temperature. Cells infected with the recombinant adenoviruses were resuspended at a density of $2.5 \times 10^{5}$ cells in $120 \mu \mathrm{l}$
$0.2 \%$ BSA medium and then seeded into the upper chamber. Then $400 \mu \mathrm{l}$ of $0.2 \%$ BSA medium containing $50 \mu \mathrm{g} / \mathrm{ml}$ human plasma fibronectin (Calbiochem, La Jolla, CA, USA) as a chemoattractant was loaded into the lower chamber. After a 24-h incubation, invaded cells on the bottom surface of the Transwell were stained with Diff-Quick solution (Sysmex, Kobe, Japan) and quantified in five selected fields ( $1 \mathrm{~mm}^{2}$ each) using a hematocytometer under a light microscope.

Soft-agar colony formation assay. Soft agar assays were constructed in 6-well plates. The foundation layer of each well consisted of $1.5 \mathrm{ml}$ of $0.6 \%$ agar solution in $1 \mathrm{X}$ media. The HCT116 cells were transduced $\left(1.5 \times 10^{4}\right.$ cells/well) for 1 day, and then mixed with $0.6 \%$ soft agar (1:1) and seeded onto the bottom. An additional $3 \mathrm{ml}$ of 1X media without agarose was poured on top of the growth layer. After a 2-week incubation, the colonies were stained with $0.05 \%$ crystal violet and photographed using an inverted microscope camera. The number of colonies was counted at x40 magnification.

Statistical analysis. All statistical analyses were performed using a t-test with SPSS 21.0 (IBM Inc., Armonk, NY, USA) software.

\section{Results}

Expression of CD44. The level of expression of CD44 mRNA was evaluated by RT-PCR; GAPDH served as an internal control. As shown in Fig. 1A, the level of expression of CD44 mRNA in cells infected with Ad-CD44-shRNA was significantly downregulated compared with parental (HCT116) and scramble-Ad-infected cells $(\mathrm{p}<0.01)$. A significant reduction in CD44 protein was also detected in Ad-CD44-shRNA-infected cells compared with scramble-Ad-infected cells $(\mathrm{p}<0.01)$.

Cell viability. The results of the cell viability assay are shown in Fig. 2. Whereas the scramble-Ad showed little cytotoxicity, 


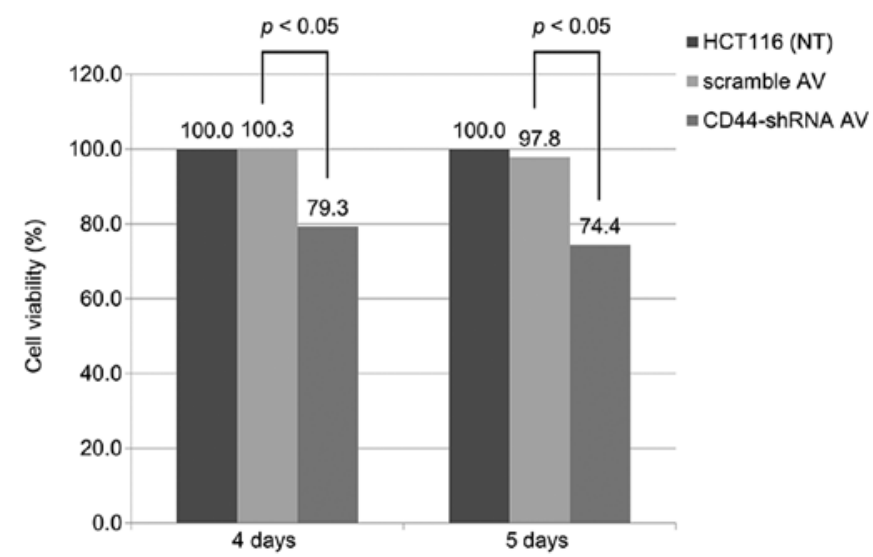

Figure 2. Cell viability was determined using CCK-8 in 4-5 days after infection with scramble Ad or Ad-CD44-shRNA.
Ad-CD44-shRNA suppressed cell viability $(\mathrm{p}<0.05)$ 4-5 days post-infection.

Flow cytometry analysis. The early (7.80\%) and late (14.65\%) apoptotic rate of Ad-CD44-shRNA-infected cells was increased compared with parental (2.58 and 6.25\%) and scramble Ad-infected (3.15 and 7.83\%) cells ( $<<0.01)$ (Fig. 3).

Cell migration assay. The Ad-CD44-shRNA-infected cells showed much lower migratory capacity than scramble-Adinfected cells at $40 \mathrm{~h}$ after plating $(\mathrm{p}<0.01)$ (Fig. 4).

Cell invasion assay. The invasion activity of Ad-CD44shRNA-infected cells was significantly decreased compared with scramble-Ad-infected cells (51.8 vs. 94.3, p<0.01) (Fig. 5).
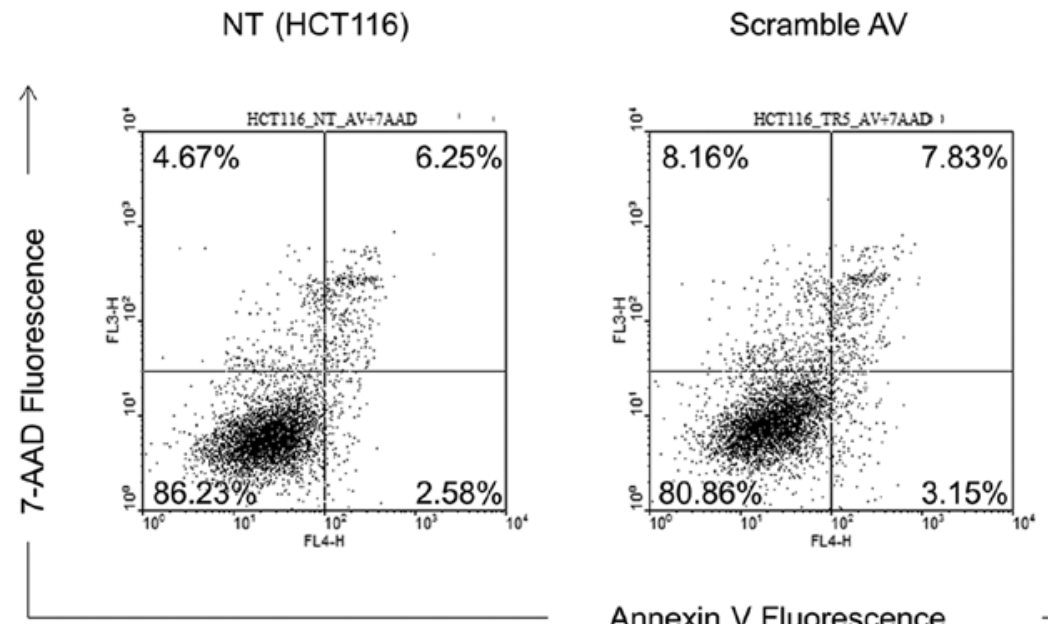

\section{Annexin V Fluorescence}

Figure 3. Apoptosis was investigated using flow cytometric analysis at $72 \mathrm{~h}$ after infection with scramble Ad or Ad-CD44-shRNA.

A
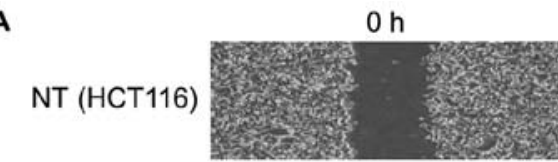

Scramble AV

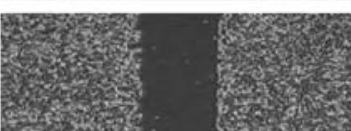

CD44-ShRNA AV

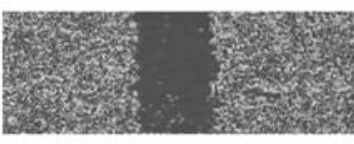

CD44-shRNAAV
$20 \mathrm{~h}$
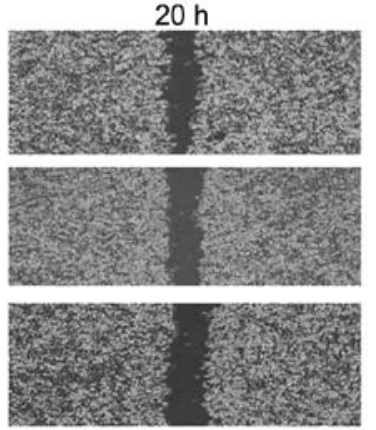

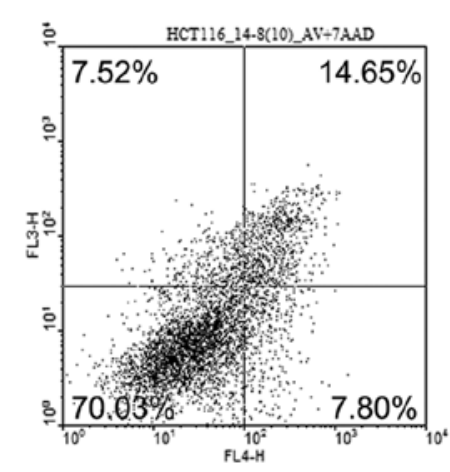

CD44-shRNA AV

B

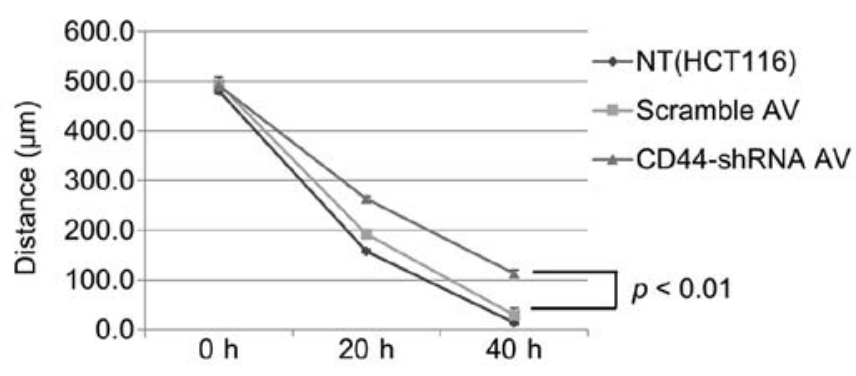

Figure 4. The effect of CD44-shRNA recombinant adenovirus treatment on cell migration. (A) Cells were photographed at 0,20, and 40 h after detachment of insert from the plate. (B) Graphs of cell migration are displayed as relative healing distance. 
A NT(HCT116)

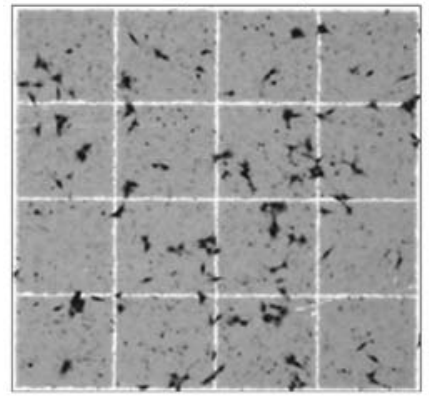

Scramble AV

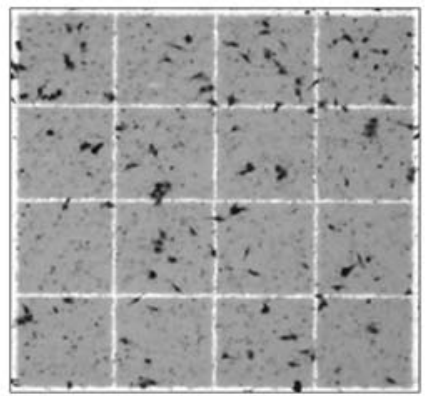

CD44-shRNA AV

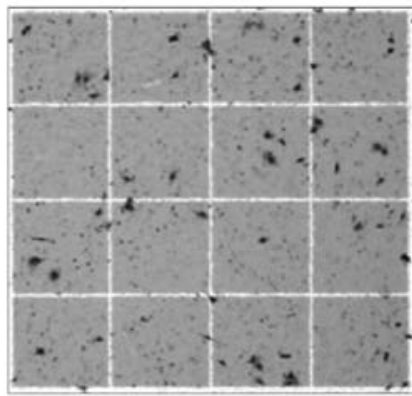

B

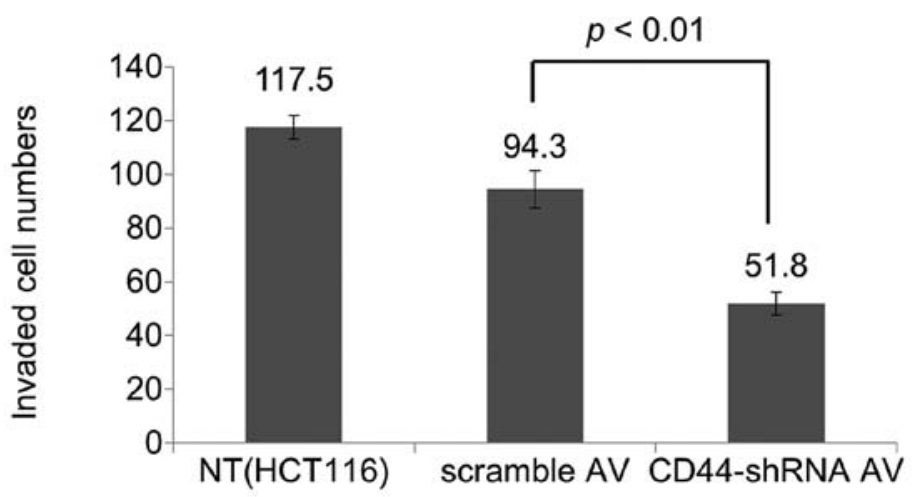

Figure 5. Effects of CD44-shRNA adenoviral vector on invasion of HCT116 cells in vitro. (A) The invasiveness of colon cancer cells were assessed using a Transwell invasion assay. The transmembrane cells were stained with Diff-Quick solution. (B) Number of invaded cells was counted at $24 \mathrm{~h}$.

A

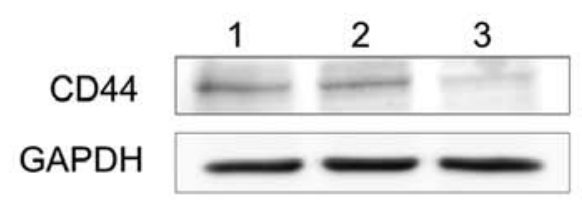

B

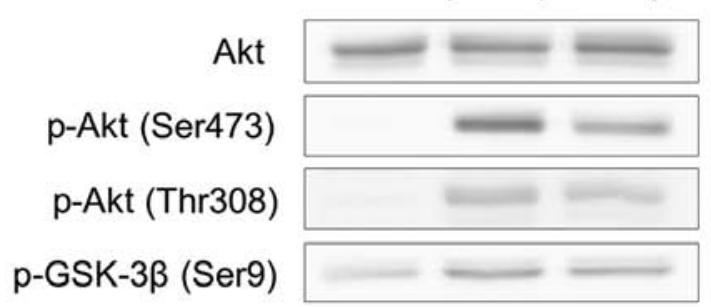

$\beta$-catenin

$\beta$-catenin
C

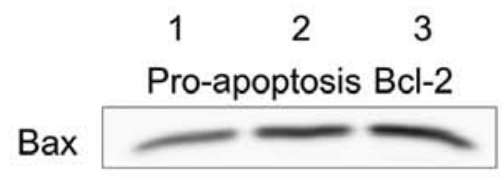

$\mathrm{Bcl}-2$

Pro-survival Bcl-2

$\mathrm{Bcl}-\mathrm{xL}$

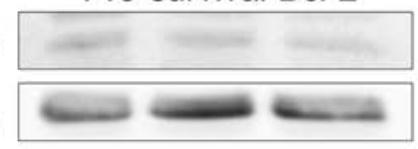

Apoptosis

Caspase-3

Cleaved caspase-3

Cleaved caspase-9

PARP
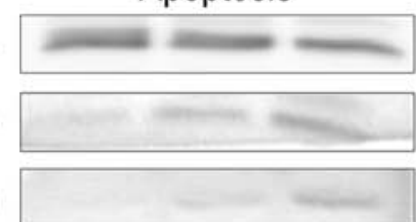

Cleaved PARP

Figure 6. Western blot analysis of (A) CD44 and GAPDH, (B) PI3-Akt signaling, and (C) apoptosis. Apoptosis and survival-related proteins were detected at $72 \mathrm{~h}$ after infection with recombinant adenoviral vectors. Lane 1, non-treated WT cells (HCT116). Lane 2, cells infected with scramble Ad. Lane 3, cells infected with Ad-CD44-shRNA.

PI3-Akt signaling and apoptosis. Western blot analysis for expression of PI3-Akt signaling and apoptotic molecules is shown in Fig. 6. The Ad-CD44-shRNA resulted in a decrease in the expression of phospho-Akt and phospho-GSK-3 $\beta$ (Fig. 6B). In contrast, there was minimal change of $\beta$-catenin expression (Fig. 6B). The Ad-CD44-shRNA also resulted 

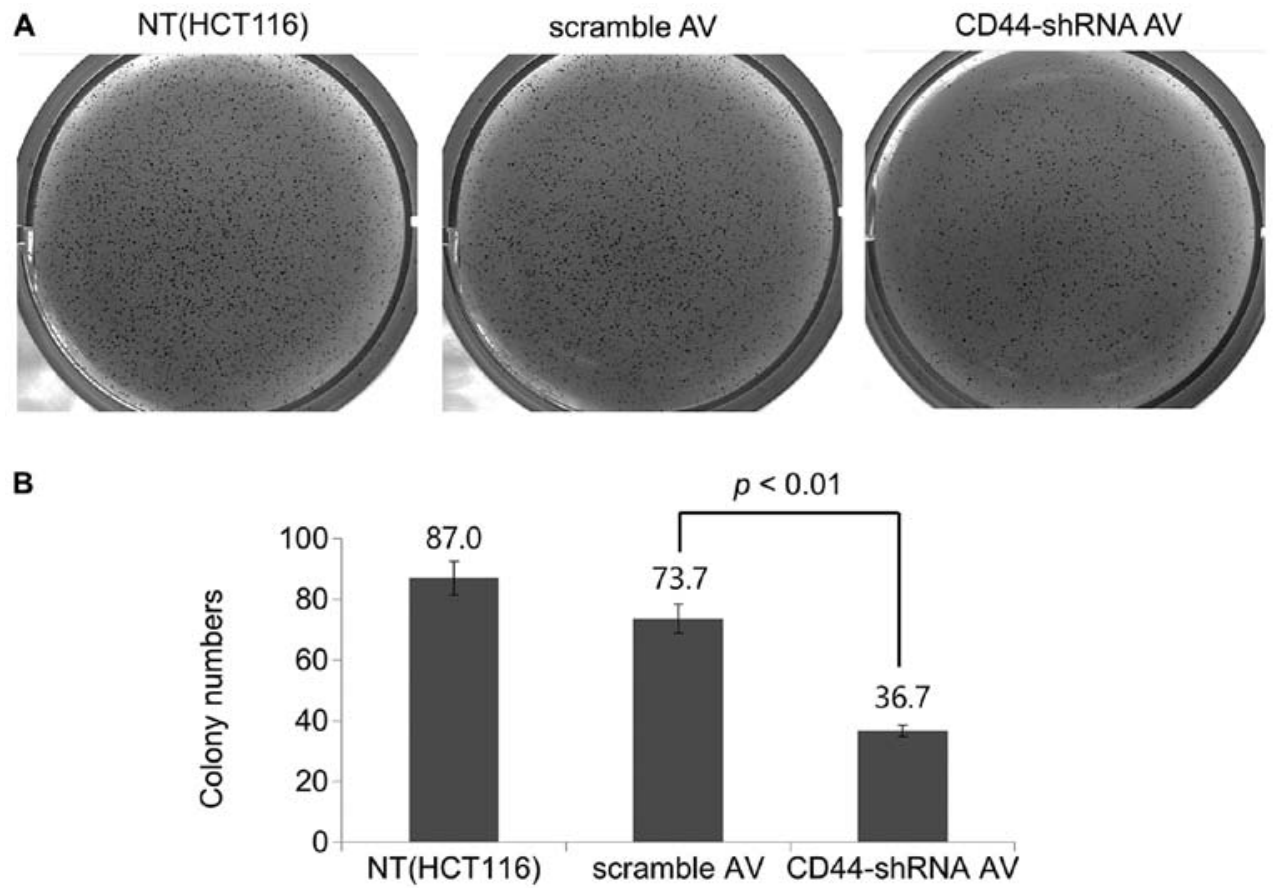

Figure 7. Soft agar colony formation assay of CD44 knockdown. (A) HCT116 cells infected with scramble Ad and Ad-CD44-shRNA was used for the soft agar colony formation assay. Cells were cultured in 3D-agar for 2 weeks, and colonies were stained with crystal violet reagent and photographed. (B) Quantitative analysis of colony numbers is shown in the lower panel.

in a decrease in the expression of Bcl-2 and Bcl-xL, but an increase in the expression of Bax, and promoted the cleavage of caspase-3, -9 and PARP (Fig. 6C).

Soft-agar colony formation assay. The Ad-CD44-shRNAinfected cells showed a marked decrease in colony formation (Fig. 7). When quantified, there was a $50.2 \%$ decrease in colony formation units in the presence of Ad-CD44-shRNA compared with scramble-Ad (Fig. 7B), suggesting a significant tumorigenic inhibition of HCT116 colon cancer cells by Ad-CD44-shRNA.

\section{Discussion}

In this study, we have constructed a recombinant adenoviral model to reduce the expression of CD44. We showed that Ad-CD44-shRNA inhibited cell proliferation, migration, and invasion in HCT116 colon cancer cells, which supports the feasibility of an adenovirus-mediated RNA interference therapy targeting colon cancer via the CD44 antigen.

Colorectal cancer is the result of genetic alterations that lead to a transformation of normal colonic epithelial cells into cancer cells. Currently, radical surgery followed by adjuvant chemotherapy is recommended to high risk patients for management of colon cancer (18). However, this standard treatment is not ideally effective because of the recurrence of the cancer and toxicity of the chemotherapeutic agents. CSCs are believed to be the reason of resistance to the conventional chemotherapy and radiotherapy that targets the bulk of cancer, leaving the stem cells unaffected (2-4). In the traditional stochastic model, every cancer cell from the bulk tumor has a carcinogenic potential. According to the hierarchical model, however, only a small proportion of tumor cells are actually cancer stem cells (4). In contrast with the stochastic model, slowly proliferating CSCs displaying multipotency and selfrenewal are only responsible for tumor initiation, maintenance, and metastasis (4). These CSCs are hypothesized to be spared from the chemotherapy that interferes with the ability of rapidly growing cells to divide (2).

To identify and isolate CSCs, there have been many efforts to identify specific CSC markers. Well-known CSC markers for colorectal cancer include CD44, CD133, EpCAM, CD24, and CD29 (4). Above all, CD44, a transmembrane glycoprotein functioning as a cell adhesion protein and a signaling receptor (6), is one of the most well-studied CSC surface markers. CD44 enhances the epithelial-mesenchymal transition, which is related to cancer cell migration and invasion (14), and therefore is associated with tumor progression, metastasis, and poor prognosis in colon cancer $(9,10,19,20)$. Importantly, inhibition of these CSC surface markers may result in the inhibition of tumor cell proliferation, invasion, and metastasis (3). We have previously developed a CD44 knockdown model using plasmids for RNA interference and reported that shRNA against CD44 inhibited cell proliferation, invasion, and migration (13). However, as mentioned above, more efficient means of delivering therapeutic siRNA are still needed because of the limited efficiency of delivery via plasmid.

In this study, we successfully constructed a recombinant adenoviral model to knock down CD44 using adenoviruses, which are among the most widely used vectors for gene therapy (21). Oncolytic virotherapy using recombinant adenoviruses has a number of potential advantages. It can be used to specifically target cancer cells while leaving normal tissue stem cells unharmed, thus minimizing systemic toxicity $(15,22)$. There is 
also a low possibility of resistance because of the diverse ways it induces oncolysis (22). Above all, therapeutic genes, such as inhibitory RNA against specific oncogenes, can be delivered using recombinant adenoviral vectors (22). Because of the high efficiency of transduction in vivo, the adenoviral system has been used for virus-based therapies $(15,23)$.

The result of this study demonstrated that reduced cell proliferation, migration, and invasion, and enhanced apoptosis were likely to be a result of the Ad-CD44-shRNA infection. Also, we showed differential expression of PI3-Akt signaling and apoptotic molecules in colon cancer cells treated with Ad-CD44-shRNA. Tumor proliferation, differentiation, and apoptosis are known to be under the control of several signaling pathways such as the Wnt signaling pathway $(24,25)$. We demonstrated that Ad-CD44-shRNA infection inhibited Akt phosphorylation (Fig. 6B), which is one of the most important Wnt-target genes for the survival of cancer cells $(26,27)$. We also showed the downregulation of GSK-3 $\beta$ (Fig. 6B), the target of PDK1/Akt signal transduction, inactivates various proteins involved in cell proliferation and survival such as $\beta$-catenin, cyclin D1, c-jun, and c-myc (28). $\beta$-catenin is a downstream molecule in the Wnt signaling pathway and plays an important role in cell-to-cell adhesion, tumor invasion, and metastasis (25). In addition, we showed decreased expression of Bcl-2 and Bcl-xL; increased expression of Bax; and cleavage of caspase-3, -9, and PARP (Fig. 6C). The Bcl-2 family proteins are key regulators of apoptosis, with a pro-survival subfamily including Bcl-2, Bcl-xL, Bcl-w, Mcl-1, and A1; and a pro-apoptotic subfamily including Bax, Bak, and Bok (29-31). Apoptosis is precipitated by the activation of cysteine proteases of the caspase family, including caspase-3, -8 and -9, and their cleavage is considered the primary hallmark of apoptosis $(32,33)$. The results of our study also demonstrated that Ad-CD44-shRNA infection induces apoptosis in HCT116 colon cancer cells, suggesting reduced clonogenic ability.

We also utilized the soft agar colony formation assay, or $3 \mathrm{D}$ culture, as a novel modality to identify the inhibition of tumorigenesis by Ad-CD44-shRNA. Because of the intrinsic difficulties in investigating the tumor progression in vivo, the soft agar colony formation assay, which is a close mimicry of the $3 \mathrm{D}$ cellular environment in vivo, has recently been used (34). With this assay, we assessed the effects of Ad-CD44shRNA on cell proliferation and migration. The result of the assay provided us with a straightforward and intuitive result, as well as a quantitative assessment of the inhibitory potential of Ad-CD44-shRNA.

Until now, there have been several clinical trials using oncolytic adenoviruses (22); however, regarding colorectal cancer, it is rarely reported (35-38). Although there is an increasing demand for novel therapeutic modalities, such as non-pathogenic viruses in the treatment of colorectal cancer, clinical evidence of oncolytic virotherapy is still lacking (22). Our results support the feasibility of an adenovirus-mediated RNA interference therapy targeting colon cancer via the CD44 antigen, which can be used as a therapeutic intervention with the anti-survival/pro-apoptotic machinery in human colon cancer. This study is also meaningful as a cornerstone to potential future gene therapies using oncolytic adenoviruses against colorectal cancer. Oncolytic adenoviral therapy, despite its limited efficacy as a single agent, has a potential role in combination therapy with conventional chemotherapy (22). Further translational studies and clinical trials focusing on the administration of cancer virotherapy in combination with conventional chemotherapy are needed.

\section{Acknowledgements}

This study was supported by a grant from Chonnam National University 2010, Research Institute of Medical Sciences, Chonnam National University (2011-CURIMS-DR007) and a Research Grant 0720570 from the National Cancer Center, Korea.

\section{References}

1. Siegel RL, Miller KD and Jemal A: Cancer statistics, 2016. CA Cancer J Clin 66: 7-30, 2016.

2. Todaro M, Francipane MG, Medema JP and Stassi G: Colon cancer stem cells: Promise of targeted therapy. Gastroenterology 138: 2151-2162, 2010.

3. Puglisi MA, Tesori V, Lattanzi W, Gasbarrini GB and Gasbarrini A: Colon cancer stem cells: Controversies and perspectives. World J Gastroenterol 19: 2997-3006, 2013.

4. Fanali C, Lucchetti D, Farina M, Corbi M, Cufino V, Cittadini A and Sgambato A: Cancer stem cells in colorectal cancer from pathogenesis to therapy: Controversies and perspectives. World J Gastroenterol 20: 923-942, 2014.

5. Dalerba P, Dylla SJ, Park IK, Liu R, Wang X, Cho RW, Hoey T, Gurney A, Huang EH, Simeone DM, et al: Phenotypic characterization of human colorectal cancer stem cells. Proc Natl Acad Sci USA 104: 10158-10163, 2007.

6. Ponta H, Sherman L and Herrlich PA: CD44: From adhesion molecules to signalling regulators. Nat Rev Mol Cell Biol 4: 33-45, 2003.

7. Ropponen KM, Eskelinen MJ, Lipponen PK, Alhava E and Kosma VM: Expression of CD44 and variant proteins in human colorectal cancer and its relevance for prognosis. Scand J Gastroenterol 33: 301-309, 1998.

8. Fernández JC, Vizoso FJ, Corte MD, Gava RR, Corte MG, Suárez JP, García-Muñíz JL and García-Morán M: CD44s expression in resectable colorectal carcinomas and surrounding mucosa. Cancer Invest 22: 878-885, 2004.

9. Huh JW, Kim HR, Kim YJ, Lee JH, Park YS, Cho SH and Joo JK: Expression of standard CD44 in human colorectal carcinoma: Association with prognosis. Pathol Int 59: 241-246, 2009.

10. Lugli A, Iezzi G, Hostettler I, Muraro MG, Mele V, Tornillo L, Carafa V, Spagnoli G, Terracciano L and Zlobec I: Prognostic impact of the expression of putative cancer stem cell markers CD133, CD166, CD44s, EpCAM, and ALDH1 in colorectal cancer. Br J Cancer 103: 382-390, 2010.

11. Harada N, Mizoi T, Kinouchi M, Hoshi K, Ishii S, Shiiba K, Sasaki I and Matsuno S: Introduction of antisense CD44S CDNA down-regulates expression of overall CD44 isoforms and inhibits tumor growth and metastasis in highly metastatic colon carcinoma cells. Int J Cancer 91: 67-75, 2001

12. Du L, Wang H, He L, Zhang J, Ni B, Wang X, Jin H, Cahuzac N, Mehrpour M, Lu Y, et al: CD44 is of functional importance for colorectal cancer stem cells. Clin Cancer Res 14: 6751-6760, 2008.

13. Park YS, Huh JW, Lee JH and Kim HR: shRNA against CD44 inhibits cell proliferation, invasion and migration, and promotes apoptosis of colon carcinoma cells. Oncol Rep 27: 339-346, 2012.

14. Cho SH, Park YS, Kim HJ, Kim CH, Lim SW, Huh JW, Lee JH and Kim HR: CD44 enhances the epithelial-mesenchymal transition in association with colon cancer invasion. Int J Oncol 41: 211-218, 2012.

15. Short JJ and Curiel DT: Oncolytic adenoviruses targeted to cancer stem cells. Mol Cancer Ther 8: 2096-2102, 2009.

16. St George JA: Gene therapy progress and prospects: Adenoviral vectors. Gene Ther 10: 1135-1141, 2003.

17. McDougal JS, Cort SP, Kennedy MS, Cabridilla CD, Feorino PM, Francis DP, Hicks D, Kalyanaraman VS and Martin LS: Immunoassay for the detection and quantitation of infectious human retrovirus, lymphadenopathy-associated virus (LAV). J Immunol Methods 76: 171-183, 1985. 
18. Chang GJ, Kaiser AM, Mills S, Rafferty JF and Buie WD; Standards Practice Task Force of the American Society of Colon and Rectal Surgeons: Practice parameters for the management of colon cancer. Dis Colon Rectum 55: 831-843, 2012.

19. Jing F, Kim HJ, Kim CH, Kim YJ, Lee JH and Kim HR: Colon cancer stem cell markers CD44 and CD133 in patients with colorectal cancer and synchronous hepatic metastases. Int J Oncol 46: 1582-1588, 2015.

20. Bendardaf R, Algars A, Elzagheid A, Korkeila E, Ristamäki R, Lamlum H, Collan Y, Syrjänen K and Pyrhönen S: Comparison of CD44 expression in primary tumours and metastases of colorectal cancer. Oncol Rep 16: 741-746, 2006.

21. Cerullo V, Koski A, Vähä-Koskela M and Hemminki A: Chapter eight - Oncolytic adenoviruses for cancer immunotherapy: Data from mice, hamsters, and humans. Adv Cancer Res 115: 265-318, 2012.

22. Bourke MG, Salwa S, Harrington KJ, Kucharczyk MJ, Forde PF, de Kruijf M, Soden D, Tangney M, Collins JK and O'Sullivan GC: The emerging role of viruses in the treatment of solid tumours. Cancer Treat Rev 37: 618-632, 2011.

23. Hawkins LK, Lemoine NR and Kirn D: Oncolytic biotherapy: A novel therapeutic plafform. Lancet Oncol 3: 17-26, 2002.

24. Logan CY and Nusse R: The Wnt signaling pathway in development and disease. Annu Rev Cell Dev Biol 20: 781-810, 2004.

25. Clevers H: Wnt/beta-catenin signaling in development and disease. Cell 127: 469-480, 2006.

26. Medema RH, Kops GJ, Bos JL and Burgering BM: AFX-like Forkhead transcription factors mediate cell-cycle regulation by Ras and PKB through p27 $7^{\mathrm{kip} 1}$. Nature 404: 782-787, 2000.

27. Zhao X, Gan L, Pan H, Kan D, Majeski M, Adam SA and Unterman TG: Multiple elements regulate nuclear/cytoplasmic shuttling of FOXO1: Characterization of phosphorylation- and 14-3-3-dependent and -independent mechanisms. Biochem J 378 : 839-849, 2004

28. Downward J: PI 3-kinase, Akt and cell survival. Semin Cell Dev Biol 15: 177-182, 2004.

29. Czabotar PE, Lessene G, Strasser A and Adams JM: Control of apoptosis by the BCL-2 protein family: Implications for physiology and therapy. Nat Rev Mol Cell Biol 15: 49-63, 2014.
30. Zheng JH, Viacava Follis A, Kriwacki RW and Moldoveanu T: Discoveries and controversies in BCL-2 protein-mediated apoptosis. FEBS J 283: 2690-2700, 2016.

31. Um HD: Bcl-2 family proteins as regulators of cancer cell invasion and metastasis: A review focusing on mitochondrial respiration and reactive oxygen species. Oncotarget 7: 5193-5203, 2016.

32. Galluzzi L, López-Soto A, Kumar S and Kroemer G: Caspases connect cell-death signaling to organismal homeostasis. Immunity 44: 221-231, 2016.

33. Man SM and Kanneganti TD: Converging roles of caspases in inflammasome activation, cell death and innate immunity. Nat Rev Immunol 16: 7-21, 2016.

34. Horibata S, Vo TV, Subramanian V, Thompson PR and Coonrod SA: Utilization of the soft agar colony formation assay to identify inhibitors of tumorigenicity in breast cancer cells. J Vis Exp e52727, 2015.

35. Nemunaitis J, Cunningham C, Buchanan A, Blackburn A Edelman G, Maples P, Netto G, Tong A, Randlev B, Olson S, et al: Intravenous infusion of a replication-selective adenovirus (ONYX-015) in cancer patients: Safety, feasibility and biological activity. Gene Ther 8: 746-759, 2001.

36. Reid TR, Freeman S, Post L, McCormick F and Sze DY: Effects of Onyx-015 among metastatic colorectal cancer patients that have failed prior treatment with 5-FU/leucovorin. Cancer Gene Ther 12: 673-681, 2005.

37. Kemeny N, Brown K, Covey A, Kim T, Bhargava A, Brody L, Guilfoyle B, Haag NP, Karrasch M, Glasschroeder B, et al: Phase I, open-label, dose-escalating study of a genetically engineered herpes simplex virus, NV1020, in subjects with metastatic colorectal carcinoma to the liver. Hum Gene Ther 17: 1214-1224, 2006.

38. Fong Y, Kim T, Bhargava A, Schwartz L, Brown K, Brody L, Covey A, Karrasch M, Getrajdman G, Mescheder A, et al: A herpes oncolytic virus can be delivered via the vasculature to produce biologic changes in human colorectal cancer. Mol Ther 17: 389-394, 2009. 